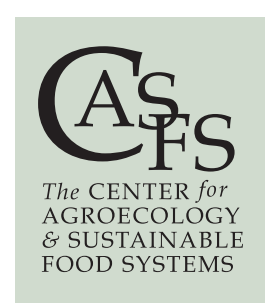

CASFS - continued from previous page

CASFS farm. The trial consists of 15 blueberry varieties with a total of 180 plants.

This is the first season that yield data were collected, and the numbers have not been crunched yet, but Leap is heartened by the trial so far. Though he had to put up bird netting over the entire trial area, it looks as if organic blueberries will grow well on the Central Coast. The berries sold exceptionally well at $\$ 4$ per half-pint - $\$ 6,000$ worth just at the UC Santa Cruz Market Cart (at the campus entrance), and they were a popular item in the farm's CSA (communitysupported agriculture) shares.
"The challenge is that blueberries need acidic soil," Leap says. Inexpensive sulfuric acid can be applied to conventionally managed blueberry fields, but Leap has had to buy vinegar approved by the Organic Materials Review Institute (OMRI) for use in certified organic systems. "We have been injecting vinegar with each irrigation. Before we planted, we applied a lot of soil sulfur and acidic soil amendments, but we still need the vinegar, and buying it in 55-gallon containers and trucking them in here might turn out to be prohibitively expensive," he says. (Also, see California Agriculture April-June 2005, Vol. 59, No. 2, p. 65 .)

\title{
UC students eating local, organic produce
}

Seven farmers local to UC Santa Cruz are partici$S$ pating in a groundbreaking farm-to-college program, supplying organic produce to the university's five campus dining rooms and restaurant. The program is running side by side with a 2-year research study on developing institutional market outlets for small and medium-sized growers.

The first program of its kind in the UC system, this is one of many farm-to-institution initiatives sprouting up around the country. Hundreds of institutions, including K-12 schools, Kaiser Permanente and UC San Francisco hospitals, and

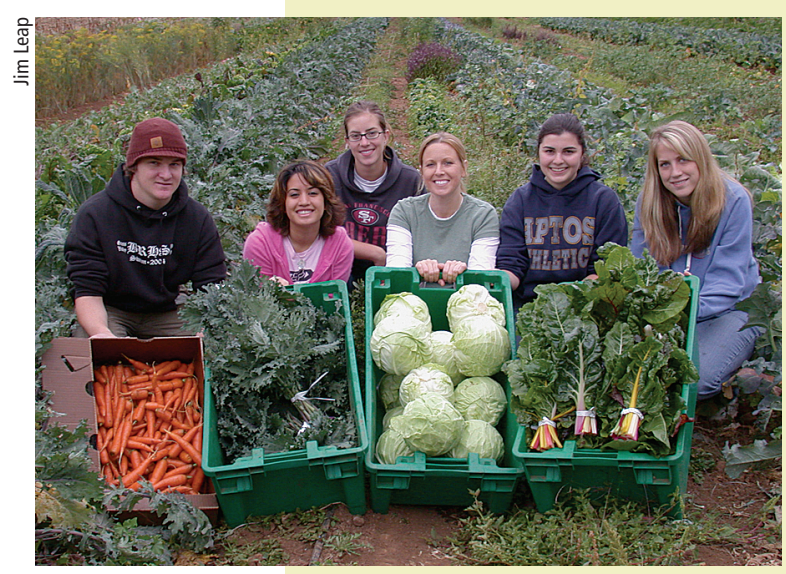
corporate cafeterias, such as Google's in Mountain View, are offering locally and sustainably grown produce. It's still a largely untapped market, says Patricia Allen, new director of the UC Santa Cruz Center

Students participate in a "Harvest for Health" activity at the UC Santa Cruz farm, part of a core course required of all first-year students in one of the campus's residential colleges. for Agroecology and Sustainable Food Systems (CASFS). "Farm-to-institution programs could be a lifeline for small to mid-scale farmers struggling to stay afloat," she says.

The seven farms supplying the UC Santa Cruz dining halls are Coke Farm, Phil Foster Ranches, Happy Boy Farms, New Natives/Greensward Nurseries, Swanton Berry Farm, Agriculture and Land-Based Training Association (ALBA), and the UC Santa Cruz farm on campus. Because the UC Santa Cruz purchasing department is not set up to contract with individual small farmers, the growers formed a consortium, Monterey Bay Organic Farming Consortium (MBOFC). ALBA acts as their umbrella organization, pooling and delivering the produce to the campus dining halls three or four times a week, invoicing the university and distributing payments to the growers.

Demand for the produce is high, from both chefs and students, but getting the program in place wasn't easy. To look in detail at the structuring and viability of institutional markets for small and medium-sized farmers, particularly those farming organically or using other environmentally sustainable farming methods, CASFS is heading up a collaborative research project. The study, which began last fall, is being funded by a $\$ 400,000$ grant from the U.S. Department of Agriculture's Cooperative State Research, Education and Extension Service (CSREES). The project directors are Allen and Shermain Hardesty, director of the UC Small Farm Center.

Specifically, the research team is studying the demand among students for food from small and medium-sized farms with sustainability criteria (for example, organic, locally grown and socially just); the produce-buying practices and preferences at California's colleges and universities; and the best produce distribution models. Results from the student survey show a definite interest in organic produce. Of the 224 returned surveys from students nationally, $47 \%$ said they wanted their college to provide organic food. Most students (53\%) wanted their college to provide food locally grown. But the highest interest among students was for food that was humanely produced $(78 \%)$, provides a living wage to workers (71\%) and sustainably produced (62\%).

Hardesty, who is surveying food-service buyers at California's colleges and universities, was "very surprised," she said, to find that about $25 \%$ of the 
The solution could be for the farm to make its own organic vinegar, Leap says. That's likely to be a job for the 6-month apprentices, who provide most of the labor for the farm. Forty years after the start of Chadwick's experiment, they continue to live on the edges of the well-cared-for fields at UC Santa Cruz, which has been dubbed the "Harvard of organic farming." - - Hazel White and Editors

\section{For more information:}

http://casfs.ucsc.edu

78 buyers she has interviewed so far already have a local buying program and 15\% are developing one. Most of those buyers said they were willing to pay a premium of around 25\% for some organic, sustainably produced, or locally grown produce. Hardesty thinks the biggest obstacle that must be addressed for local producers to gain greater access to institutional markets is the need for a consolidated delivery system.

Gail Feenstra, food systems analyst with the UC Sustainable Agriculture Research and Education Program (SAREP), is heading up the research on distribution infrastructures for getting regional produce to institutional cafeterias. "This is very new," Feenstra says, "and it's going to take a number of years" to get the optimal infrastructures worked out, but chefs and food service directors want local food, and "some big players are starting to change their buying contracts" to include requirements for sustainably grown food.

If that trend toward sustainability criteria being part of institutional contracts continues, it will be the catalyst for significant environmental and social change. Allen foresees more than an improvement in the eating habits of millions of Americans. Contract criteria might include wage and benefits requirements for workers and reductions in toxic pesticides, she says, and then "a huge market could be transformed with an incentive-based approach, rather than through regulation."

The UC Santa Cruz farm-to-college program has adopted sustainability criteria: all the produce is grown within 250 miles of Santa Cruz and is certified organic; in addition, ALBA is a "workersupportive" company. This year it is expected that $30 \%$ of the UC Santa Cruz dining services department's produce purchases will meet the criteria.

From the start, students have been the driving force behind the UC Santa Cruz program, but it's also true that most of the 15,000 students

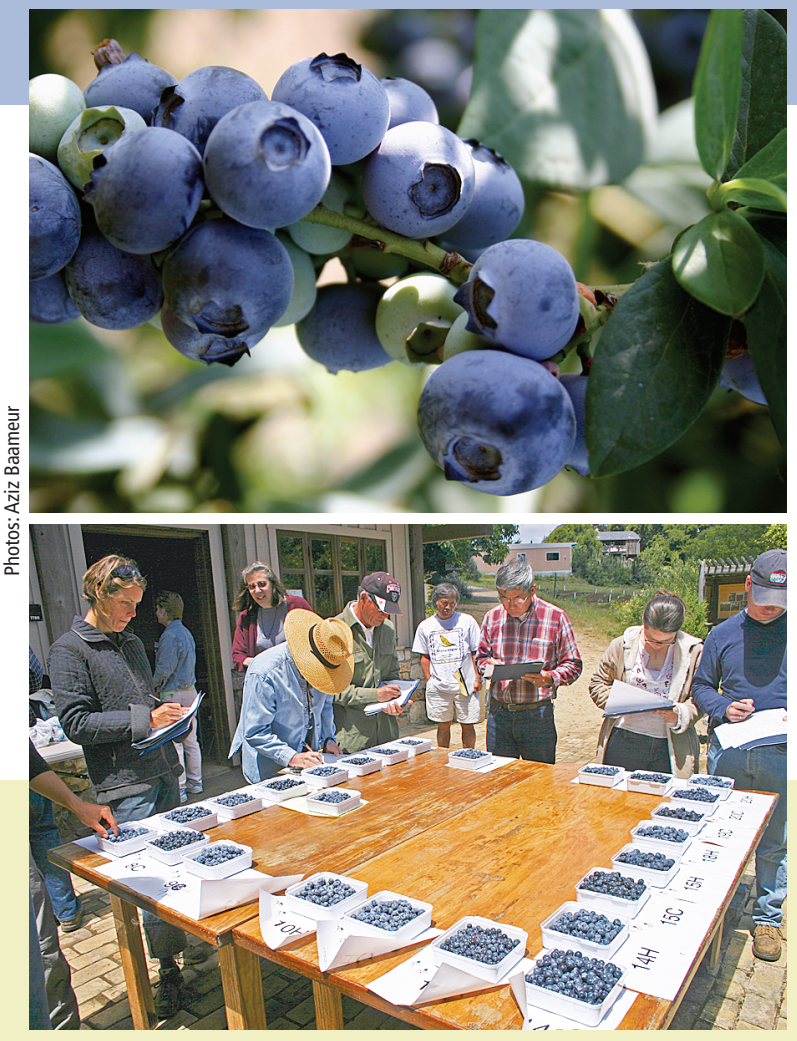

have never visited a farm. With funding from the True North Foundation and the Wallace Genetic Foundation, CASFS last year hired Nancy Vail to support campus education and outreach, which is helping ensure the momentum for the program continues. Demand from student meal-plan holders is the key to its ongoing success.

The UC Santa Cruz program has been successfully exported to other UC campuses. Tim Galarneau, CASFS coordinator of that effort, says commitment to sustainable food purchasing "is sweeping through the university system in a very exciting way." He reports that UC Santa Barbara and UC Davis have adopted sustainability criteria and are exploring local sourcing; Stanford University already has a contract with ALBA; and UC Berkeley is being supplied with sustainably grown food through the Growers Collaborative, which is affiliated with the Community Alliance with Family Farmers.

Galarneau is also coordinator of a statewide student movement urging the UC Regents to adopt purchasing guidelines that reflect principles of sustainability. He is also working with the housing directors on all UC campuses to develop a sustainable food policy for the entire UC system. Working collaboratively, the students, campus administrators and community organizations promise to be the strong allies local growers need to break into the farm-to-college market. - Hazel White

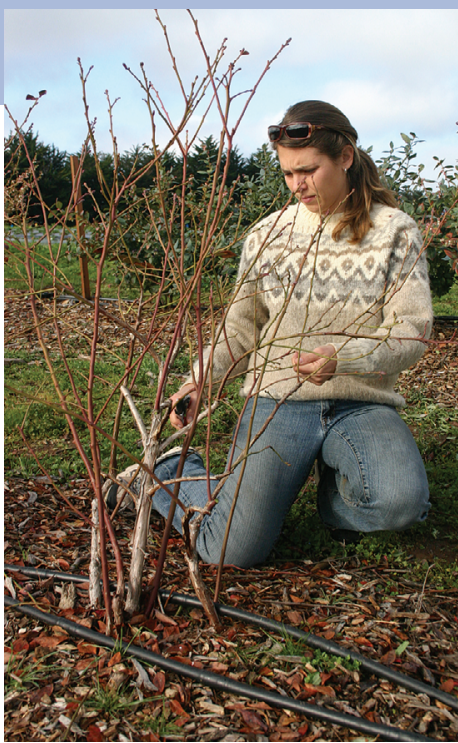

At the UC Santa Cruz farm, 15 varieties of blueberries are being field-tested for taste and adaptability to coastal growing conditions. Clockwise from top left: a blueberry cluster; a plant is pruned by a farm employee; workshop participants evaluate varieties for color, size, sweetness and other qualities.
For more information:

http://casfs.ucsc.edu/farm2college 